\title{
Mecanismos de Queixas e Reclamações para Gestão de Conflitos na Construção de Linhas de Transmissão
}

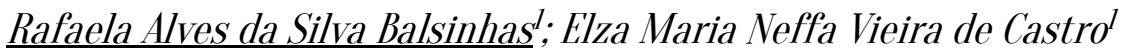 \\ \rafaelabalsinhas@gmail.com
}

1. Programa de Pós-Graduação em Meio Ambiente (PPGMA) da Universidade do Estado do Rio de Janeiro.

\section{Histórico do Artigo:}

Recebido em: 23 de abril de $2020 \quad$ Aceito em: 03 de novembro de $2020 \quad$ Publicado em: 30 de abril de 2021

\begin{abstract}
Resumo: Partindo do pressuposto de que os conflitos ambientais ocorrem, ou são acirrados, quando da implantação de empreendimentos potencialmente poluidores, o presente estudo se propõe a dialogar com a literatura acadêmica que estuda os procedimentos adotados para a gestão ambiental dos grandes projetos de infraestrutura. Para tal, analisa-se a implementação do Programa de Comunicação Social (PCS) de uma linha de transmissão de energia elétrica em fase de obras, em especial, seus mecanismos de queixas e reclamações. 0ptou-se por uma abordagem quali-quantitativa dos relatórios e do banco de dados do sistema de ouvidoria, que busca atender as demandas de diferentes partes interessadas através de canais de atendimento criados exclusivamente para esse fim. A análise aborda a quantidade de chamados, os principais meios utilizados, os assuntos tratados e os prazos de atendimento. 0s resultados evidenciam que a análise dos documentos do sistema de ouvidoria pode auxiliar na identificação de danos ambientais sistêmicos e verificação da efetividade das medidas de controle ambiental, contribuindo no entendimento de como este tipo de projeto afeta a qualidade de vida das populações. Conclui-se a que 0 sistema de ouvidoria pode contribuir para manutenção de um canal de diálogo com a população afetada pelo empreendimento, evitando o acirramento das tensões ocasionadas pelo projeto de engenharia.

Palavras-chave: Mecanismos de Queixas e Reclamaações, Licenciamento Ambiental, Comunicação Social, Linhas de transmissão.
\end{abstract}

\section{Grievance Redress Mechanism for Conflict Management During the Construction of Electric Power Transmission Lines}

Abstract: This study starts with the premise that environmental conflicts can occur or be incited when implementing projects that can potentially cause pollution. The present study proposes a dicuss with the academic literature that studies the procedures adopted for the environmental management of large infrastructure projects. For this, the implementation of the Social Communication Program (PCS) for an electric power transmission line under construction is analyzed, specifically its grievance redress mechanisms. A quali-quantitative approach was selected for the ombudsman system reports and database, which seeks to meet the demands of different stakeholders through service channels created exclusively for this purpose. The analysis covers call volume, principal means used, subjects discussed and service wait times. The results show that the analysis of the ombudsman system documents can assist in the identification of systemic environmental damage and verification of the environmental control measures effectiveness, contributing to the understanding of how this type of project affects the quality of life of the population. The conclusion reached is that the ombudsman system can contribute to maintaining a channel for continued dialogue with the population affected by the project, avoiding the escalation of tension caused by the engineering project.

Keywords: Grievance Redress Mechanism, Environmental Licensing, Social Communication Program, Transmission lines. 


\section{Mecanismos de Quejas y Reclamos para la Gestión de Conflictos en la Construcción de Líneas de Transmisión}

Resumen: Partiendo del supuesto de que los conflictos ambientales ocurren, o se intensifican, al implementar emprendimientos potencialmente contaminantes, este estudio propone dialogar con la literatura académica que estudia los procedimientos adoptados para la gestión ambiental de grandes proyectos de infraestructura. Para ello, analizamos la implementación del Programa de Comunicación Social (PCS) de una línea de transmisión de energía eléctrica en fase de obras, en particular, sus mecanismos de quejas y reclamos. Se optó por un abordaje cualitativo y cuantitativo de los informes y base de datos del sistema de ombudsman, que busca atender las demandas de los diferentes grupos de interés a través de canales de atención creados exclusivamente para este fin. El análisis aborda el número de llamadas, los principales medios utilizados, los temas tratados y las condiciones del servicio. Los resultados muestran que el análisis de los documentos del sistema de ombudsman puede ayudar en la identificación de daños ambientales sistémicos y verificación de la efectividad de las medidas de control ambiental, contribuyendo a comprender cómo este tipo de proyectos afecta la calidad de vida de las poblaciones. Se concluye que el sistema de ombudsman puede contribuir a mantener un canal de diálogo con la población afectada por el proyecto, evitando la intensificación de las tensiones provocadas por el proyecto de ingeniería.

Palabras clave: Mecanismos de Quejas y Reclamos, Licenciamiento Ambiental, Comunicación Social, Líneas de transmisión.

\section{INTRODUÇÃo}

0 meio ambiente é considerado um bem difuso que transcende o desejo de um indivíduo ou grupo social (SIRVINKAS, 2018, p.111). Contudo, diversos são os casos em que há legitimidade de certas formas de uso e apropriação do espaço sobre outras (ASCERALD et al., 2009). Nesses casos podem ocorrer situações de conflito ambiental, caracterizadas pelo "desacordo no interior do arranjo espacial de atividades de uma localidade ou região”, que acarretam o confronto de interesses e de visões de mundo sendo, muitas vezes, uma “(...) ameaça da continuidade de um tipo de ocupação do território pela maneira como outras atividades, espacialmente conexas, são conduzidas" (ASCERALD, 2005 apud FLEURY et al., 2014, p. 64).

Reconhecendo a diversidade de interesses sobre o território e as diferentes assimetrias que caracterizam os sujeitos e os grupos sociais, sejam elas de caráter material, cognitivoinformacional, político-organizativo e culturais, o Estado deve assumir o papel de mediador no processo de gestão ambiental (QUINTAS, 2009). Esse trabalho assume que conflitos ambientais podem ocorrer ou serem acirrados quando há implantação e/ou operação de empreendimentos que utilizam elementos da natureza, realizam atividades potencialmente poluidoras ou são capazes de causar degradação ambiental.

Esses empreendimentos são submetidos ao licenciamento ambiental, instrumento da Política Nacional do Meio Ambiente brasileira, a Lei $n^{0}$ 6.938, de 31 de agosto de 1981 (BRASIL, 1981). Por meio deste procedimento, são identificados e avaliados os impactos ambientais desses 
Mecanismos de Queixas e Reclamações para Gestão de Conflitos na Construção de Linhas de Transmissão

projetos na vida dos sujeitos e/ou nos grupos sociais afetados, bem como estabelecidas medidas para prevenção, mitigação e/ou compensação para os efeitos considerados negativos. Nessa perspectiva, Acselrad et al (2009) consideram que a avaliação de impacto ambiental e a aplicação das medidas de controle ambiental podem contribuir para reduzir ou ratificar situações de injustiça ambiental.

Os conflitos socioambientais resultantes da implantação e operação de grandes projetos de infraestrutura tem sido objeto de estudo por autores alinhados à Ecologia Política (ZHOURI et al., 2007, OLIVEIRA, 2007; PEREIRA, PENID0, 2010) e à Antropologia do poder (BR0NZ, 2016; SIGAUD, 1986). Apesar de haver ampla discussão acadêmica acerca dos conflitos causados por grandes projetos, sobretudo os hidrelétricos e de mineração, no que se refere à transmissão de energia elétrica esse debate é reduzido (P0RT0 et al, 2009, p.1987), embora essa tipologia seja fundamental para a referida cadeia de valor de energia elétrica. Estudos recentes (CARDOSO JÚNIOR et al, 2019; DEMORI, 2019; SANTOS, 2017, SUGAWARA, 2016; ARAÚJ0, 2016) têm trabalhado a questão da avaliação dos impactos ambientais para os sistemas de transmissão, considerada fundamental para a tomada de decisão quanto à viabilidade dos empreendimentos no âmbito do licenciamento ambiental (DUARTE et al, 2017). Porém, não utilizam os conflitos ambientais como uma categoria de análise, por partirem de outro olhar teórico-metodológico, alinhado ao campo da avaliação de impacto ambiental.

Publicações que tratam da tipologia de transmissão de energia elétrica tendem a salientar os impactos nos meios físico e biótico em detrimento dos impactos sociais ocasionados pelas linhas de transmissão localizadas, sobretudo, em propriedades rurais do país. Araújo (2016, p.46) informa que publicações do Ministério de Minas Energia e da Empresa de Pesquisa Energética recomendam a localização das linhas de transmissão preferencialmente em "áreas em processo de antropização ou com acessos já abertos”, buscando-se evitar interferências sobretudo em áreas legalmente protegidas ou com vegetação nativa. Ressalva-se, nestas recomendações, interferências em terras indígenas, áreas urbanas e peri-urbanas e projetos de assentamento.

Em função da possibilidade de ajustes de traçado, as linhas de transmissão em geral não demandam desapropriações e/ou remoção de população. Por sua vez, a instalação de faixa de servidão administrativa, área contígua ao empreendimento que implica restrições de uso do solo por questões de segurança, provoca uma nova conformação espacial do espaço (PORTELA, 2013, p77). Embora seja permitido o uso desta área para pastagem, circulação de animais e mesmo para agricultura, principalmente de cunho familiar, não são toleradas culturas propícias 
ao fogo como a cana-de-açúcar e a existência de espécies de alto estrato, ou ainda aquelas que demandam 0 uso intensivo de maquinário.

No entanto, outras tipologias, como projetos de hidrelétricas com reservatório e jazidas minerais, requerem a remoção total da população para que a área possa ser explorada economicamente. Ainda que as linhas de transmissão não demandem a remoção de população, elas podem apresentar grandes extensões e afetar diferentes espaços geográficos e a dinâmica socioeconômica de grupos sociais (P0RTELA, 2013, p.77-78).

Desse modo, este trabalho reconhece o licenciamento ambiental de linhas de transmissão com um espaço de conflitos socioambientais, por excelência, por elas provocarem uma nova conformação socioespacial. E se propõe a dialogar com a literatura acadêmica que estuda os impactos ambientais e os procedimentos adotados para a gestão ambiental dos grandes projetos de infraestrutura, analisando a implementação do Programa de Comunicação Social (PCS) de uma linha de transmissão em fase de obras, uma obrigatoriedade legal em muitos empreendimentos licenciados. Em geral, o PCS tem por finalidade a criação de um canal de comunicação com as partes interessadas do projeto (proprietários de terras, moradores de localidades do entorno do empreendimento, gestores públicos, entre outros), partindo da divulgação de informações sobre o empreendimento e seus impactos com base nos diálogos estabelecidos. Neste sentido, é um programa estratégico do ponto de vista da informação, posto que possui interface com os demais Programas Ambientais e envolve uma diversidade de partes interessadas.

Vale destacar que o empreendedor - empresa que possui a concessão pública para realização das atividades de obras e posterior funcionamento - é o responsável por todo o projeto, inclusive pelo desempenho dos Programas Ambientais como o PCS. Contudo, dada à especificidade técnica, é comum a contratação de conjunto de empresas de consultoria ambiental para execução dessas atividades. Assim, sobre os PCS, pode-se afirmar que:

\footnotetext{
"reúne um conjunto de atividades e rituais comunicativos que promovem uma aproximação direta dos consultores e empreendedores com as comunidades locais, organizações e membros da gestão governamental (BRONZ, 2016, p. 282).”
}

No bojo das estratégias do PCS estão os mecanismos de queixas e reclamações, que visam a encaminhar os conteúdos das manifestações das partes afetadas à ciência do empreendedor para consequente tratativa. Os mecanismos são diversos, desde caixa de sugestões, registros realizados a partir do contato face a face pela equipe, como aplicativos de celular. Uma importante ferramenta neste contexto é o sistema de ouvidoria. Esse sistema comumente 
Mecanismos de Queixas e Reclamações para Gestão de Conflitos na Construção de Linhas de Transmissão

implantado no âmbito dos projetos sob licenciamento ambiental (não se limitando às linhas de transmissão) tem como principais canais uma linha telefônica gratuita e e-mail específico para atendimento da população. Busca privilegiar os contatos feitos diretamente pela população, com mediação reduzida das equipes técnicas que não privilegiam o diálogo com as partes afetadas, de forma a evitar ruídos na comunicação ou geração de informação não consoante ao procedimento acordado com o órgão ambiental. Os registros feitos por meio deste sistema seguem um rito específico de formalização: as demandas devem ser documentadas, compartilhadas para as pessoas indicadas pelo empreendedor para responder à reclamação ou solicitação do assunto em questão, e respondidas no prazo estabelecido. Cabe destacar que os prazos para a resposta são definidos de acordo com a realidade de cada projeto.

Os registros das manifestações, que incluem as datas dos contatos, dados pessoais do manifestante e conteúdo da sua manifestação, são documentados no Banco de Dados e seus resultados são apresentados nos Relatórios encaminhados ao órgão ambiental. Eles compõem o que Bronz denomina como "peças técnicas do licenciamento" (2016, p. 292), sobre as quais, "a caracterização social é apresentada de modo descritivo e enciclopédico", diferente das ferramentas de gestão das empresas, como o Banco de Dados, nos quais "o conflito social se torna, muitas vezes, o objeto do exame”. Assim, a análise na íntegra desses registros, para além dos relatórios técnicos, pode auxiliar na identificação de situações de conflito, sejam oriundas de impactos ambientais não considerados no processo de avaliação de impacto, sejam pela baixa "efetividade" das medidas de controle ambiental adotadas.

Contudo, é importante considerar os limites desta análise, a partir do reconhecimento de que o registro por meio dos canais da ouvidoria é realizado por um conjunto de pessoas menor do que as afetadas adversamente, seja por desconhecimento dos canais, por dificuldades materiais para contactar o sistema ou mesmo pela descrença no processo de interlocução com grandes empresas. Entende-se, ainda, que as tratativas (ou respostas) apresentadas partem da tomada de decisão dos empreendedores, empresas contratadas e sua equipe (assumindo aqui que há uma relação de poder marcada pela relação cliente-contratado, ainda que as empresas contratadas respondam tecnicamente pelas ações realizadas), tanto em relação aos processos inerentes ao projeto quanto à implementação das medidas dos Programas Ambientais previstos. Mesmo assim, entende-se que as informações disponíveis são importantes fontes para compreender como os projetos afetam a qualidade de vida das populações. 


\section{METODOLOGIA}

0 presente estudo adota a abordagem quali-quantitativa na análise descritiva das informações referentes ao processo de ouvidoria inerente ao licenciamento ambiental do maior sistema de transmissão de energia elétrica do Brasil. A seleção deste projeto deve-se à sua importância e abrangência no país, tendo em vista que, ao todo, 5 estados da federação, 83 municípios e mais de 3.000 propriedades, sobretudo rurais, são tocados pela linha de transmissão que atravessa suas áreas. Isto significa dizer que o empreendimento afeta populações e pessoas com diferentes características e dinâmicas socioambientais.

De acordo com o Estudo de Impacto Ambiental deste projeto (XRTE/CONCREMAT, 2016), pode-se dizer que a fase de obras é a etapa com maior número de impactos ambientais previstos, em comparação com a fase de planejamento e operação. É também durante essa fase que os conflitos são mais expressivos, Visto que os grupos sociais das áreas de influência começam a ser afetados pelas atividades e pelos impactos ambientais. São, portanto, conflitos concretos, experimentados no cotidiano das populações com 0 início das atividades construtivas.

$\mathrm{Na}$ análise realizada, dois fundamentos teóricos foram considerados. Por um lado, o pressuposto de que os projetos de engenharia de empreendimentos de infraestrutura fazem parte de um modelo econômico e social assimétrico, como demonstram os estudos da Ecologia Política e da Antropologia do Poder. Por esta razão, tais análises salientam o meio ambiente, que é tratado no processo administrativo de licenciamento ambiental como sendo uma arena de disputas e de conflitos de uso, apropriação e simbologia do espaço (ACSERALD, 2014, p.7). Por outro, a base metodológica de avaliação de impactos ambientais privilegia às tecnicidades que buscam entender a cadeia de causa e efeito sob a ótica da previsibilidade, não explorando a relação de poder existente nas relações de força que acarretam os conflitos.

$\mathrm{Na}$ análise pretendida sobre o sistema de ouvidoria foram considerados os dados e as informações disponíveis no Sistema Eletrônico de Informações (SEI) do processo de licenciamento ambiental do empreendimento em análise, conduzido pelo Instituto Brasileiro do Meio Ambiente e dos Recursos Naturais Renováveis (IBAMA). Foram examinados os seguintes documentos: o Estudo de Impacto Ambiental, o Plano Básico Ambiental (PBA) - no qual são descritas as diretrizes do PCS -, os Relatórios Semestrais de acompanhamento da execução do referido programa na fase de obras e o Relatório de Solicitação de Licença de Operação (XRTE/CONCREMAT, 2019a; XRTE/CONCREMAT, 2019 b), que abrange dados do período de agosto 
Mecanismos de Queixas e Reclamações para Gestão de Conflitos na Construção de Linhas de Transmissão

de 2017 a outubro de 2018. Adicionalmente, o Banco de Dados da 0uvidoria também foi analisado, apresentado como anexo dos referidos relatórios, informando dados primários sobre as manifestações, como as datas da primeira manifestação e de resposta formal pela ouvidoria, bem como a descrição do conteúdo da manifestação e da respectiva devolutiva.

Importa destacar que o Banco de Dados apresenta duas classificações: a primeira trata do teor crítico das manifestações, com três classes: reclamações, solicitações - quando haviam pedidos de esclarecimentos que demandavam resolução por parte da empresa - e denúncias; e a segunda relaciona-se ao assunto, à motivação da manifestação na ouvidoria, com 8 classes: fundiário; licenciamento ambiental; restrição do uso do solo; interferências no cotidiano; relacionamento com as empreiteiras/terceiras; risco das atividades; trabalho e arrecadação e outros.

Dessa forma, foram realizadas análises acerca das manifestações registradas no sistema de ouvidoria na fase de obras sobre a quantidade de chamados por mês e a sua correlação com o cronograma de implantação do projeto; os meios de comunicação mais utilizados pelas partes afetadas para realização das suas manifestações (e-mail, 0800 ou contato face a face) e os prazos de atendimento das manifestações, considerando o prazo estipulado no processo de licenciamento ambiental. Também foram examinadas as duas classificações apresentadas no Banco de Dados deste empreendimento que tratam do teor e do conteúdo das manifestações relacionadas ao projeto de transmissão de energia elétrica.

\section{RESULTADOS E DISCUSSÃ0}

Conforme mencionado no PBA do empreendimento em questão, o PCS estava relacionado como uma parte da estratégia de mitigação de 14 impactos ambientais previstos, a saber:

\footnotetext{
“Geração de expectativa da população; interferências em áreas produtivas; indução ao extrativismo da vegetação nativa com a abertura da faixa de servidão; possibilidade da prática da caça; possibilidade de acidentes com a fauna; eventuais transtornos decorrentes da obra e operação; conflito entre a mão de obra e a população local; aumento na mobilização e organização social devido à presença do empreendimento; incremento no tráfego local; alteração do sistema viário; possibilidade de interferência na segurança pública; geração de empregos; dinamização da economia local e; interferência com comunidade quilombola Malhadinha (XRTE/CONCREMAT, 2017, p.372-373)."
}

Além disso, o Programa era justificado "não só em função dos impactos socioambientais identificados, mas pela busca de um relacionamento proativo e marcado pela responsabilidade social entre o empreendedor e a sociedade" (XRTE/CONCREMAT, 2017, grifo nosso). 
No conjunto das medidas de comunicação social previstas, o sistema de ouvidoria era caracterizado como "importante e rápido instrumento de comunicação entre a população e empresas em geral” (XRTE/CONCREMAT, 2017, p.388). Por prever meios gratuitos de interlocução - chamadas telefônicas através do número 0800 e troca a correspondência eletrônica por meio de um e-mail específico - inferia-se que o sistema "mobilizava uma participação proativa da população” (XRTE/CONCREMAT, 2017, p. 388, grifo nosso).

Neste documento, foram estabelecidos os procedimentos gerais relativos ao fluxo de informações da ouvidoria. Este se daria:

“(...) através de registro nos formulários, indicando o dia de entrada e de resposta das solicitações, questionamentos e encaminhamentos definindo o prazo para retorno ao solicitante (estabelecido como de até 72 horas. 0 banco de dados de registros e encaminhamentos da ouvidoria será encaminhado como anexo aos relatórios de andamento de execução do programa (de comunicação social). (XRTE/CONCREMAT, 2017, p. 380).”

Também foi estabelecida a operacionalização de:

“(...) um mecanismo de avaliação do atendimento por parte do usuário, para manifestação do grau de satisfação da resposta. (...) Os resultados dessas verificações serão consolidados e apresentados nos relatórios de andamento de execução do programa. (XRTE/CONCREMAT, 2017 p. 380).”

Com bases nessas diretrizes, os relatórios semestrais apresentavam informações operacionais sobre o processo adotado para documentação dos chamados e seus principais resultados. Vale sinalizar uma menção relevante do relatório que informa sobre as manifestações recebidas e documentadas diretamente pelo empreendedor, sendo a empresa consultora responsável pelo suporte para atendimentos e respostas aos registros recebidos (XRTE/CONCREMAT, 2019). Cabe destacar que este arranjo entre empreendedor e a consultoria pode se estabelecer de diferentes formas nos processos de licenciamento ambiental. Neste caso, a palavra suporte indica a função da consultoria em obter, das várias equipes técnicas que atuam no projeto, as diferentes respostas para as manifestações. Também indica a responsabilidade da consultoria em documentar o processo, incluindo as respostas finais.

Por meio dos relatórios, também se verifica que a divulgação do sistema de ouvidoria ocorreu, essencialmente, em contatos face a face da equipe técnica responsável pela execução do programa, além da divulgação dos canais de comunicação em todas as peças gráficas produzidas no âmbito do projeto, tais como folders, cartazes e manuais educativos. 
Mecanismos de Queixas e Reclamações para Gestão de Conflitos na Construção de Linhas de Transmissão

Durante o período de 14 meses de realização das obras documentados nos relatórios mencionados, o sistema de ouvidoria recebeu o total de 176 registros, sendo a média de 12,6 chamados por mês, tendo sido registrado o máximo de 27 chamados no pico ano de obra, em agosto de 2018. Em consonância com o esperado pela equipe do PCS, o número de chamados do sistema em análise aumentou conforme 0 avanço das atividades construtivas. Verifica-se, assim, que o desenvolvimento das obras torna "concreto" os seus impactos associados.

A maioria dos chamados foi realizada através de contato telefônico (85\%), o que sugere que a população afetada por este projeto tenha menos acesso ao correio eletrônico, seja pela conveniência e rapidez do contato telefônico gratuito ou por dificuldades de acesso à internet e/ou, ainda, por falta de computador na área rural, onde o empreendimento se situa, majoritariamente.

0 quantitativo dos chamados é de difícil inferência, posto que a ausência de registros dos canais de ouvidoria pode estar relacionada, tanto a questões objetivas quanto subjetivas, indo desde a dificuldade de acesso às tecnologias como telefone e internet até a percepção de que a documentação das queixas não resultaria em respostas efetivas. Sendo assim, sugerir uma métrica a priori sem se basear nos resultados da implantação de ouvidoria em projetos similares poderia ter pouca efetividade nas análises. Apesar disso, dado o número de municípios e de proprietários afetados pelo projeto pode-se sugerir que houve subnotificação dos registros de reclamações e de pedidos de esclarecimentos. Esse resultado pode estar associado aos limites dos contatos face a face para divulgação dos canais de ouvidoria, realizados pela equipe técnica com múltiplas atribuições, como se indica no PBA.

Além disso, o baixo número de chamados pode ter sido intensificado pela adoção da estratégia de divulgação da ouvidoria, realizada sobretudo por meio de peças gráficas que acabam por dificultar o acesso da população com poucos anos de estudo ou mesmo analfabeta. A divulgação por spot de rádio ou de carros de som não foi mencionada nos Relatórios analisados, mas são estratégias comumente utilizadas na disseminação de informações no âmbito do licenciamento ambiental nas áreas rurais ou mesmo nas áreas urbanas das cidades de pequeno porte (BRONZ, 2019, p. 28). Também vale registrar que não foram utilizados meios alternativos ligados à internet, como a divulgação de informações nas redes sociais ou estabelecimento de contatos por aplicativos com o WhatsApp, o que poderia ter ampliado a participação, sobretudo da população urbana, com maior acesso aos referidos meios de comunicação. 
A análise do Banco de Dados permite verificar que $65 \%$ dos chamados foram classificados como reclamações, 32\% como solicitações (incluindo pedidos de esclarecimentos e encaminhamento de tratativas) e 3\% como denúncias. Contudo, a análise do banco de dados disponibilizado não apresenta quaisquer informações sobre os chamados classificados como denúncia, não sendo possível o conhecimento do teor destas manifestações. Tal decisão pode estar relacionada à possível proteção do denunciante e/ou das partes envolvidas, porém não possibilita ao órgão ambiental analisar o conteúdo destas denúncias e, assim, realizar possíveis endereçamentos aos demais órgãos competentes.

Conforme indicado no primeiro relatório semestral de acompanhamento dos Programas Ambientais submetido ao órgão ambiental (XRTE/CONCREMAT, 2019a), o conteúdo dos registros das reclamações e solicitações eram classificados em oito classes, mencionadas anteriormente, de acordo com o teor do seu conteúdo. Do total de registros, $56 \%$ dos atendimentos foram classificados em interferências no cotidiano, qualificados como perturbações da dinâmica social por meio das atividades construtivas. Por sua vez, $22 \%$ tratavam da questão fundiária, isto é, relacionavam-se aos processos de valoração da indenização posta pela instituição da faixa de servidão administrativa, que implica restrições de uso do solo e, portanto, da dinâmica local.

As manifestações referentes às interferências no cotidiano abarcam uma gama de reclamações que envolvem as dinâmicas construtivas. Contudo, chama atenção que, no bojo dessa classe genérica, a maioria (56\%) dos registros tratavam do uso dos acessos viários já existentes pelos veículos do empreendimento e da abertura de novos acessos para uso da empresa construtora até os locais de instalação das torres. Nota-se que o aumento do tráfego de veículos, principalmente em trechos de menor uso precedente ao empreendimento, pode afetar as atividades socioculturais e econômicas que exigem deslocamentos de diferentes naturezas - ir e vir ao trabalho e aos locais de convergência social e/ou entrega e recebimento de insumos e serviços.

Foram manifestadas reclamações sobre a piora das condições originais dos acessos pela passagem de maior número de veículos pesados; prejuízos causados aos veículos de menor porte pelas inadequadas condições viárias, aumento do risco de acidente devido ao desrespeito à legislação de trânsito (alta velocidade) e, por fim, aumento da ressuspensão do material particulado (poeira) nas estradas não pavimentadas pelo aumento da frequência de veículos e maquinários.

As situações relacionadas aos acessos suscitaram incômodos à população diretamente afetada pelo projeto, além de perturbar indiretamente as demais pessoas que compartilham 0 
Mecanismos de Queixas e Reclamações para Gestão de Conflitos na Construção de Linhas de Transmissão

uso das vias. Apesar de não manifestado na documentação analisada, o poder público também pode ser uma parte afetada negativamente por esse impacto, posto que a manutenção viária é sua atribuição e a população a ele recorre para adequações.

É importante registrar, ainda, que a questão da utilização dos acessos e da piora das suas condições pelas atividades das obras foram consideradas por três dos impactos ambientais apresentados no EIA, a saber: incremento no tráfego local; alteração do sistema viário e possibilidade de eventuais transtornos decorrentes da obra e da operação. Portanto, também deveriam ser alvo de análise e atenção das demais equipes envolvidas no licenciamento, como saúde e segurança, posto que o incremento do tráfego e a baixa manutenção das vias pelos organismos competentes pode causar maiores riscos de acidentes.

Ademais, cabe lembrar que o contínuo monitoramento dessas vias pode contribuir para a tomada de decisão assertiva das medidas preventivas e de controle ambiental, no sentido de prevenir acidentes de trânsito e possíveis tensões com a população local e com o poder público em função da deterioração da qualidade de determinado acesso viário pelo tráfego contínuo de veículos e maquinários da obra.

A segunda classe de manifestação reunia os chamados relacionados aos problemas fundiários ligados ao processo de instalação de faixas de servidão. Na análise desses chamados, verifica-se que a maioria dos requerentes desconhecia os critérios para o pagamento de indenização, sendo comum ocorrer manifestações de surpresas quando da instalação de torres no terreno e/ou de construção de acessos a estas. A transparência na comunicação voltada aos processos indenizatórios confere legitimidade aos mesmos.

No caso deste projeto, aproximadamente $25 \%$ dos registros da ouvidoria voltavam-se à questão fundiária, o que se mostra relevante principalmente pelo conteúdo das manifestações, marcadas pela desconfiança dos requisitos que compuseram os valores indenizatórios. Tal resultado poderia indicar a necessidade de reforço na capacitação das equipes que trabalham com essa temática e na divulgação adequada de informações sobre os critérios de valoração das indenizações e prazos previstos para pagamento, bem como os direitos dos proprietários (que preveem a possibilidade de encaminhamento da questão por via judicial, caso não haja acordo).

Percebe-se, assim, que as atividades da equipe fundiária também permeiam importantes ações de comunicação, muitas vezes com proprietários em situação de vulnerabilidade socioambiental. Ações específicas que respeitem as singularidades socioeconômicas desses proprietários devem ser estabelecidas previamente à negociação da indenização. A inclusão destas medidas contribuiria para o atendimento dos princípios básicos apresentados no 
Programa de Instituição da Faixa de Servidão Administrativa, que mencionava a necessidade de haver "tratamento universal, pluralidade de opções e direito de negociação" quando da autorização da passagem do empreendimento pelos territórios (XRTE/CONCREMAT, 2017, p.290).

Ainda sobre essa questão, destacamos que apenas 1\% das dúvidas manifestadas no sistema de ouvidoria esteve relacionada às restrições de uso do solo com a instituição da faixa de servidão administrativa, o que não garante o pleno conhecimento do tema pelos proprietários, residentes e trabalhadores do local. A justificativa apresentada no Relatório de Solicitação de Licença de Operação (XRTE/CONCREMAT, 2019 b), sobre o pequeno percentual destaca a atuação in loco da equipe de comunicação responsável por fazer esclarecimentos aos proprietários. Contudo, o baixo percentual também pode indicar que os proprietários, residentes e trabalhadores destas áreas sequer tenham tomado conhecimento dessas restrições com 0 cenário de instalação e operação do empreendimento. Esse desconhecimento pode implicar riscos à segurança dos mesmos e do próprio sistema de transmissão de energia elétrica, além de possibilitar o surgimento de futuros conflitos quando da utilização da área da faixa de servidão em desconformidade com as restrições impostas pelo projeto de engenharia.

Por fim, cabe salientar que as dificuldades de atendimento aos prazos acordados com 0 órgão ambiental para resposta às manifestações do Sistema de Ouvidoria pelo próprio empreendedor podem acirrar tensões e causar perda de credibilidade do processo, principalmente para as partes interessadas afetadas adversamente. Para este empreendimento, o tempo de reposta de 72 horas foi estabelecido no PBA. Contudo, há indicação de que, nos relatórios, as 72 horas mencionadas para a resposta no PBA foram interpretadas como 5 (cinco) dias úteis para as manifestações, exceto em casos de questionamentos mais complexos que requeiram levantamento de dados e consulta jurídica, como as classes Fundiário e Interferências no cotidiano, que totalizaram 78\% dos registros. Para estes, o prazo de atendimento era de 12 (doze) dias úteis, podendo ser ampliado desde que justificado, caso fosse identificada a necessidade de levantamento de informações mais qualificadas para o pleno atendimento da demanda.

Sobre o atendimento ao prazo, importa destacar que a resposta ao manifestante não significa, necessariamente, a resolução do problema. Ainda assim, 63\% dos casos considerados complexos foram encerrados além do prazo previsto, sendo que $11 \%$ dos chamados foram resolvidos em até 20 dias úteis e os outros $42 \%$ foram atendidos acima desta marca. Para além das dificuldades técnicas, o baixo atendimento aos prazos estipulados pode demostrar uma maior necessidade de engajamento das equipes envolvidas no atendimento dos chamados, 
Mecanismos de Queixas e Reclamações para Gestão de Conflitos na Construção de Linhas de Transmissão

inclusive construtoras e empresas subcontratadas, de modo a priorizar os contatos estabelecidos via ouvidoria, posto que elas são manifestações claras de conflito com o empreendimento.

\section{CONSIDERAÇÕES FINAIS}

Considerando que o próprio licenciamento ambiental se configura como um campo de conflito, cuja gênese advém da escolha de um modelo social com assimetrias socioambientais, o presente estudo buscou contribuir para o debate sobre as tensões presentes no processo de licenciamento ambiental do maior sistema de transmissão de energia elétrica do país, a partir das manifestações realizadas na ouvidoria.

Parte fundamental das estratégias de comunicação social, o sistema de ouvidoria objetiva estabelecer um canal de diálogo com a população afetada pelo projeto, de forma a evitar o acirramento das tensões ocasionadas pelo projeto. Neste sentido, mais do que abordar a quantidade de chamados e os prazos de atendimento da ouvidoria do referido empreendimento, o estudo apresenta considerações quanto aos meios mais utilizados pelas partes afetadas de forma adversa para as manifestações e o conteúdo das principais queixas e solicitações relacionadas ao projeto de transmissão de energia elétrica.

A análise identificou que as manifestações documentadas pelo sistema de ouvidoria foram uma resposta aos impactos do projeto para os diferentes públicos-alvo. Tratavam-se, em geral, de situações em que o conflito era manifestado por meio de canais fornecidos pelo próprio empreendedor, podendo ser compreendido como uma importante ferramenta de gestão, ainda que fosse uma obrigatoriedade legal prevista no processo de licenciamento. Em geral, os chamados registrados pela ouvidoria tratavam as interferências das obras no cotidiano das populações e eram considerados complexos, de difícil resolução, o que demandava um prazo amplo para o seu encaminhamento, fosse pelas dificuldades técnicas de atendimento ou pelo baixo engajamento nas respostas das equipes envolvidas neste processo.

Em geral, os registros foram realizados através de meios que favorecem o contato a distância, como telefone e correspondência eletrônica. Contudo, isso não exclui a importância da manutenção das estratégias de comunicação realizadas face a face pela equipe do PCS e sua adequada documentação. Os relatórios pouco informam sobre as tratativas realizadas diretamente pelas equipes situadas nas áreas de intervenção, o que não significa que não tenham existido. 0 mais provável é que as tratativas presenciais não tenham sido documentadas 
e divulgadas adequadamente para o órgão ambiental. Neste sentido, o registro de todos os contatos referentes às queixas e reclamações, incluindo àqueles realizados de forma presencial, deve ser apresentado no processo de licenciamento como uma oportunidade de melhoria dos mecanismos de comunicação e de governança do projeto. Apesar de não tratar diretamente sobre os canais de ouvidoria, Bronz conclui que a "comunicação eletrônica parece não ter dirimido a importância dos eventos presenciais em nossa sociedade” (2016, p. 288).

A documentação das tratativas realizadas entre a equipe envolvida do sistema de ouvidoria e os diversos públicos estabelece um compromisso de retorno ao manifestante, fato que pode reduzir o acirramento das tensões pela formalização e gestão do processo. A análise e o monitoramento da documentação acerca das queixas e reclamações realizadas oportuniza a verificação de problemas sistêmicos do projeto, além de possibilitar a obtenção de informação para melhoria da estratégia de comunicação com os beneficiários e partes adversas. Adicionalmente, gera subsídios para a implementação de medidas corretivas durante a vigência do projeto, podendo reduzir outras situações de conflito. Ainda, seu exame permite extrair informações relevantes para o planejamento de projetos com características similares, possibilitando tanto uma aprendizagem institucional para as empresas e equipes envolvidas, como para o próprio órgão ambiental, um importante ente no processo de gestão ambiental pública.

Assim, com base nas informações do sistema de ouvidoria, este estudo reflete sobre como os mecanismos de queixas e reclamações podem ser fortalecidos e contribuem para evitar a produção ou ratificação de injustiças ambientais no processo de licenciamento. Nessa perspectiva, almeja que as suas contribuições possam ser utilizadas na implementação de mecanismos de queixas e reclamações de outras linhas de transmissão e tipologias similares, desde que resguardadas suas características e singularidades.

\section{REFERÊNCIAS BIBLIOGRÁFICAS}

ACSELRAD, H.; CAMPELLO, C.; BEZERRA, G. 0 que é Justiça Ambiental. 1º. ed. Rio de Janeiro: Garamond, 2009.

ACSELRAD, H. Apresentação. In: Zhouri, A.; LASCHEFSKI, K.; PEREIRA, D.B. A insustentável leveza da política ambiental: desenvolvimento e conflitos socioambientais. Belo Horizonte: Autêntica, 2014.

ARAUJ0, F. R. N. Coordenação de dados, valores e participação de atores na tomada de decisão em estudos de alternativas locacionais de linhas de transmissão: uma proposta utilizando modelagem espacial e análise multicriterial. Universidade Federal de Minas Gerais, Instituto de Geociências, 2016.

BRASIL. LEI No 6.938, de 31 de agosto de 1981. Dispõe sobre a Política Nacional do Meio Ambiente, seus fins e mecanismos de formulação e aplicação, e dá outras providências. Diário Oficial [da] República Federativa do Brasil, Brasília, DF, 02 set.1981. 
BR0NZ, D. Nos bastidores do licenciamento ambiental: uma etonografia das práticas empresariais em grandes empreendimentos. Rio de Janeiro: Contra Capa, 2016.

. Do campo etnográfico ao campo político: uma análise dos bastidores do

licenciamento ambiental. Guarimã - Revista de Antropologia \& Política, Vol. 1, N 1, AgostoDezembro de 2019, p. 9-35.

CARDOSO JÚNIOR, R. A. F.; HOFFMANN, A. S. Environmental licensing for transmission systems and electricity sector planning in Brazil. Energy Policy, v. 132, p. 1155-1162, 2019.

DEMORI, V. A. Efetividade transativa do sistema de AIA federal de sistemas de transmissão de energia elétrica. Tese de Doutorado. Universidade de São Paulo, 2019.

DUARTE, C. G,; DIBO, A.A.; SÁNCHEZ, L.E. What Does The Academic Research Say About Impact Assessment And Environmental Licensing In Brazil?. Ambiente e Sociedade (Campinas), v. 20, p. 261-292, 2017

IBAMA. Guia de Avaliação de Impacto Ambiental para Sistemas de Transmissão de Energia. Brasília: IBAMA, 2019.

FLEURY, L. C.; ALMEIDA, J.; PREMEBIDA, A. 0 ambiente como questão sociológica: conflitos ambientais em perspectiva. Sociologias, Porto Alegre , v. 16, n. 35, p. 34-82, Apr. 2014 . Disponível em: $\langle\mathrm{http}$ ://www.scielo.br/scielo.php?script=sci_arttext\&pid=S1517-452220140001000038̂lng=enfnrm=iso $>$. Acesso em 26 set. 2019.

OLIVEIRA, R. S. TEIXEIRA; ZHOURI, A. Desenvolvimento, Conflitos Sociais e Violência no Brasil Rural: o caso das usinas hidrelétricas. Ambiente e Sociedade (Campinas), v. X, p. 119-135, 2007.

PENID0, M. 0; PEREIRA, D. B. Conflitos em empreendimentos hidrelétricos: possibilidades e impossibilidades do (des)envolvimento social.In: ZHOURI, A.:LASCHEFSKI, K. (Org.). Desenvolvimento e Conflitos Ambientais. Belo Horizonte: Editora da UFMG, 2010, v. 1, p. 250-275.

PORTO, M. F.; MILANEZ, B. Eixos de desenvolvimento econômico e geração de conflitos socioambientais no Brasil: desafios para a sustentabilidade e a justiça ambiental. Ciência \& saúde coletiva, v. 14, p. 1983-1994, 2009.

PORTELA, F. Faixas de servidão de linhas de transmissão de Energia elétrica e os lucros cessantes na Cajucultura: métodos e valoração da limitação do uso do solo em territórios produtivos. Espaço \& Geografia, Vol.16, No 1 (2013), 67:95.

QUINTAS, J. S. Educação no processo de gestão pública: a construção do ato pedagógico. In: LOUREIR0, C.F.B; CASTR0, R.S.(Orgs.) Repensar a educação ambiental: um olhar crítico. São Paulo: Cortez, 2009.

SANTOS, A. W. 0 licenciamento ambiental e o planejamento integrado da geração e transmissão de energia elétrica: limitações e desafios para o Brasil. Rio de Janeiro, 2017. 178p. Dissertação de Mestrado - Departamento de Engenharia Civil, Pontifícia Universidade Católica do Rio de Janeiro.

SIGAUD, L. Efeitos sociais de grandes projetos hidrelétricos: as barragens de Sobradinho e Machadinho. In: R0SA, L.P. et. al. Impactos de grandes projetos hidrelétricos e nucleares. Rio de Janeiro: Marco Zero, 1986.

SIRVINSKAS, L. P. Manual de direito ambiental. São Paulo: Saraiva Educação, 2018.

SUGAWARA, T. R. S. Licenciamento Ambiental: acompanhamento de Implantação de Linhas de Transmissão no Estado de São Paulo. Faculdade de Saúde Pública da Universidade de São Paulo, São Paulo, 2016.

XRTE/CONCREMAT. Estudo de Impacto Ambiental. XRTE/CONCREMAT: Rio de Janeiro, 2016.

Plano Básico Ambiental. XRTE/CONCREMAT: Rio de Janeiro, 2017.

$1^{\circ}$ Relatório Semestral do Sistema de Transmissão Xingu-Rio. XRTE/CONCREMAT: Rio de Janeiro, 2019 a. 
Relatório de Solicitação de Licença de 0peração do Sistema de Transmissão Xingu-Rio. XRTE/CONCREMAT: Rio de Janeiro, 2019b.

ZHOURI, A.; OLIVEIRA, R. Desenvolvimento, conflitos sociais e violência no Brasil rural: o caso das usinas hidrelétricas. Ambiente e Sociedade, vol. 10, n. 2, p. 119-135, 2007. 